\title{
ИНТРАОПЕРАЦИОННАЯ ОЦЕНКА НЕПОСРЕДСТВЕННЫХ РЕЗУЛЬТАТОВ ПОСЛЕДОВАТЕЛЬНОГО КОРОНАРНОГО ШУНТИРОВАНИЯ
}

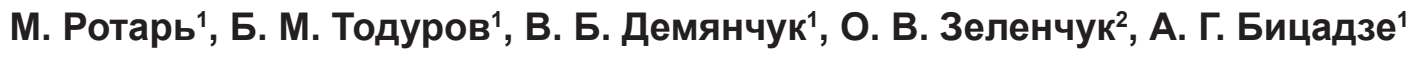 \\ 'Институт сердца МЗ Украины, г. Киев, \\ ${ }^{2}$ Национальная медицинская академия последипломного образования имени П. Л. Шупика, г. Киев

\section{INTRAOPERATIVE ESTIMATION OF IMMEDIATE RESULTS OF SUBSEQUENT CORONARY SHUNTING}

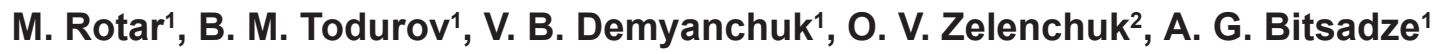 \\ ${ }^{1}$ Institute of the Heart, Kiev, \\ ${ }^{2}$ Shupyk National Medical Academy of Postgraduate Education, Kiev
}

\begin{abstract}
Реферат
Цель. В настоящее время существуют разногласия относительно целесообразности использования кондуитов при операции коронарного шунтирования (КШ) с наложением последовательного или линейного шунта. Цель исследования: оценить параметры кровотока в шунтах разной конструкции.

Материалы и методы. Обследованы 145 пациентов, у которых по поводу ишемической болезни сердца (ИБС) и многососудистого атеросклеротического поражения венечных артерий (BA) в клинике выполнена операция КШ. Параметры кровотока в линейных и последовательных шунтах оценивали и сравнивали по данным фрлоуметрии.

Результаты. Во всех последовательных шунтах отмечены хорошие параметры объемной скорости кровотока (ОСК) - (70,6 \pm $30,2)$ мл/мин, низкое сопротивление кровотока (пульсовой индекс - PI 1,8); в линейных шунтах - соответственно ОСК - (37,5 \pm 20,5) мл/мин, PI 2,1.

Обсуждение. Высокая частота ранней окклюзии шунтов часто обусловлена ошибочным выбором техники операции КШ. Флоуметрия является эффективным инструментом периоперационного контроля качества наложенных анастомозов, помогает избежать ранней окклюзии аутографта.

Выводы. Высокие показатели ОСК и низкое сопротивление кровотока по последовательным коронарным шунтам подтверждают целесообразность широкого применения метода при многососудистом КШ.

Ключевые слова: последовательное коронарное шунтирование; интраоперационная допплерометрия; фрлоуметрия; объемная скорость кровотока; пульсовой индекс.

Abstract

Objective. Today disagreements exist about expediency of the conduits application in a coronary shunting (CSH) operations, when the shunt is formatted in subsequent or linear method. The investigation objective was to estimate blood flow parameters in the shunts of different construction.

Materials and methods. There were examined 145 patients, in whom operation of $\mathrm{CSH}$ was performed in the clinic for an ischemic heart disease and multivascular atherosclerotic affection of coronary arteries. Flowmetry data was used for estimation and comparison of the blood flow parameters in subsequent and linear shunts.

Results. In all subsequent shunts good parameters of the volume blood flow velocity (VBFV) was noted $-(70.6 \pm 30.2) \mathrm{ml} / \mathrm{min}$, and low resistance of blood flow (the pulse index - PI 1.8); in linear shunts - accordingly, VBFV - $(37.5 \pm 20.5) \mathrm{ml} / \mathrm{min}, \mathrm{PI} 2.1$.

Discussion. High rate of early occlusion of the shunts was caused frequently by technical mistakes while doing CSH procedure. Flowmetry constitutes effective instrument of perioperative control of the formatted anastomoses quality, and helps to prevent the autograft early occlusion.

Conclusion. High indices of VBFV and low resistance of blood flow along subsequent coronary shunts confirm the expediency of wide application of the method in the multivessels CSH.

Keywords: subsequent coronary shunting; intraoperative dopplerometry; flowmetry; the volume blood flow velocity; the pulse index.
\end{abstract}

Коронарное шунтирование (КШ) - метод лечения ИБС, который позволяет эффективно улучшить качество и увеличить продолжительность жизни пациентов [1]. Несмотря на широкое применение артериальных кондуитов для шунтирования ВА, венозные шунты являются основными в ежедневной практике кардиохирурга. Это обусловлено, в первую очередь, тем, что в на- стоящее время КШ выполняют у пациентов при сложном, многососудистом атеросклеротическом поражении ВА, и использование даже двух грудных артерий не может решить вопрос полной реваскуляризации миокарда. Кроме того, венозные кондуиты незаменимы в ситуациях, когда КШ осуществляют в неотложном порядке или у пациентов после ранее выполненных операций на сердце. Хирургическая техника КШ постоянно совершенствуется в целях достижения лучших и долговечных результатов. Одним из таких приемов реваскуляризации миокарда является использование последовательных, или «прыгающих» шунтов. По результатам клинических исследований установлена эффективность такого вида шунтирования [25]. Однако вопрос о целесообразно- 
сти применения последовательных шунтов обсуждается, поскольку выводы об их пользе были сформулированы до внедрения интраоперационной флоуметрии.

Целью исследования был анализ параметров кровотока по последовательным и линейным венозным шунтам по данным прямой интраоперационной флоуметрии.

\section{МАТЕРИАЛЫ И МЕТОДЫ ИССЛЕДОВАНИЯ}

В период 2015 - 2016 гг. операция аортокоронарного шунтирования (АКШ) в клинике выполнена у 145 пациентов по поводу ИБС. У 82 пациентов (группа 1) осуществлено последовательное шунтирование двух и более BA, у 63 пациентов (группа 2) использовали только линейные шунты. Основные клинические характеристики пациентов, сравнительные данные ангиографии и оперативные вмешательства представлены в табл. 1, 2. Возраст пациентов группы 1 в среднем $(64,2 \pm 4,7)$ года, группы $2-(63,4 \pm 6,2)$ года.

Операцию выполняли по стандартной методике: срединная стернотомия, вскрытие перикарда, канюляция аорты и правого предсердия. Искусственное кровообращение проводили в условиях умеренной гипотермии - $(32 \pm 0,5)^{\circ} \mathrm{C}$. Системное перфузионное давление поддерживали на уровне 55 - 65 мм рт. ст. Всем больным устанавливали дренаж в левый желудочек через правую верхнюю легочную вену

Таблица 1. Основные клинические характеристики пациентов исследованных групп

\begin{tabular}{|lcc|}
\hline \multicolumn{1}{|c|}{ Показатель } & Величина показателя, \% в группах \\
\cline { 2 - 3 } & $1(\mathrm{n}=82)$ & $2(\mathrm{n}=63)$ \\
\hline Мужчин\% & 62,2 & 54 \\
\hline Сахарный диабет & 36,6 & 36,5 \\
\hline Гипертоническая болезнь & 76,8 & 77,8 \\
\hline Гиперхолестеринемия & 93,9 & 93,7 \\
\hline Хронические заболевания легких & 15,8 & $15, .9$ \\
\hline Цереброваскулярные события & 10,8 & 11,1 \\
\hline Почечная недостаточность & 3,6 & 3,2 \\
\hline ФВ ЛЖ менее 40\% & 10,8 & 12,7 \\
\hline Инфаркт миокарда в анамнезе & 29,3 & 31,7 \\
\hline Аневризма Лж & 12,2 & 12,7 \\
\hline
\end{tabular}

Примечание. ФВ ЛЖ - фракция выброса левого желудочка.

и левое предсердие. У большинства больных проводили искусственную фибрилляцию желудочков с интермиттирующим пережатием аорты, кроме больных, у которых АКШ сочетали с операцией на клапане аорты, для защиты миокарда применяли кардиоплегию раствором Custadiol в устье ВА. У всех пациентов при наложении дистальных анастомозов применяли интракоронарные шунты. Технику и геометрию наложения дистальных анастомозов выбирали индивидуально, в соответствии с анатомией сердца и расположением шунтируемых сосудов. Дистальные анастомозы линейных и последовательных шунтов с ВА накладывали конец в бок, промежуточные анастомозы «прыгающих» шунтов - бок в бок. Использовали различную технику соединения кондуита и ВА:

- параллельно - разрез на шунте и ВА продольно оси сосудов, анасто- моз накладывали параллельно осей разрезов;

- перпендикулярно (ромбовидно), или анастомоз по типу «Diamond shape» («бриллиантовая грань») - разрез на шунте и ВА продольно оси сосудов, анастомоз накладывали перпендикулярно этих осей [6];

- под углом к оси ВА - разрез на шунте и ВА продольно оси сосудов, анастомоз накладывали под углом от 0 до 90 оси шунта к оси ВА.

Всем пациентам проводили исследования после отключения аппарата искусственного кровообращения (АИК), достижения среднего артериального давления около 70 мм рт. ст., частоты сокращений сердца 70-80 в 1 мин. Для интраоперационного исследования параметров кровотока по шунтам использовали флоуметр нового поколения (Medistim VeriQ VQ4122C, Medi-Stim AS,

Таблица 2. Сравнительные данные ангиографии и выполненных операций

\begin{tabular}{|c|c|c|}
\hline \multirow{2}{*}{ Показатель } & \multicolumn{2}{|c|}{ Величина показателя в группах } \\
\hline & $1(n=82)$ & $2(n=63)$ \\
\hline \multicolumn{3}{|l|}{ Поражение сосудов по данным ангиографии } \\
\hline трех, абс. (\%) & $58(70,7)$ & $44(69,8)$ \\
\hline двух, абс. (\%) & $14(17,1)$ & $10(15,9)$ \\
\hline одного, абс. (\%) & - & - \\
\hline основного ствола левой ВА, абс. (\%) & $10(12,2)$ & $9(14,3)$ \\
\hline \multicolumn{3}{|l|}{ Операции } \\
\hline плановые & 64 & 47 \\
\hline неотложные & 18 & 16 \\
\hline АКШ, МКШ & 72 & 54 \\
\hline АКШ, МКШ, устранение аневризмы ЛЖ & 10 & 8 \\
\hline Число дистальных анастомозов на одного пациента ( $\bar{x} \pm m)$ & $3,02 \pm 0,34$ & $2,97 \pm 0,45$ \\
\hline Число линейных шунтов & 76 & 187 \\
\hline Последовательные - 2 артерии (число дистальных анастомозов) & $78 / 148$ & 0 \\
\hline Последовательные - 3 артерии (число дистальных анастомозов) & $8 / 24$ & 0 \\
\hline
\end{tabular}

Примечание. МКШ - маммарокоронарное шунтирование. 
Таблица 3 Оценка кровотока по шунтам в исследованных группах

\begin{tabular}{|c|c|c|}
\hline \multirow{2}{*}{ Показатель } & \multicolumn{2}{|c|}{ Величина показателя в группах $(\bar{x} \pm m)$} \\
\hline & 1 & 2 \\
\hline \multicolumn{3}{|l|}{ ОСК по шунту, мл/мин } \\
\hline линейному & $38,4 \pm 21,1$ & $37,5 \pm 20,5$ \\
\hline последовательному (2 артерии) & $53,8 \pm 24,5$ & $37,5 \pm 20,5^{*}$ \\
\hline последовательному (3 артерии) & $70,6 \pm 30,2$ & $37,5 \pm 20,5^{*}$ \\
\hline дистальной части последовательного шунта & $36,9 \pm 18,9$ & $37,5 \pm 20,5$ \\
\hline \multicolumn{3}{|l|}{ PI по шунту } \\
\hline линейному & $2,1 \pm 1,0$ & $2,0 \pm 1,1$ \\
\hline последовательному & $1,8 \pm 0,4$ & $2,0 \pm 1,1^{*}$ \\
\hline дистальной части последовательного шунта & $1,9 \pm 0,6$ & $2,0 \pm 1,1$ \\
\hline
\end{tabular}

Осло, Норвегия). Кровоток оценивали по показателям: ОСК в графте, PI - отражает сопротивление тока крови в области анастомоза.

$\mathrm{PI}=\mathrm{Vmax}-\mathrm{Vmin} / \mathrm{Vmean}$,

где Vmax-максимальная скорость потока во время систолы;

Vmin-минимальная скорость кровотока во время диастолы;

Vmean-среднее значение потока. Диастолическое наполнение

(DF\%) коронарного русла $=\mathrm{Vd} / \mathrm{Vs}+\mathrm{Vd} \times 100$,

где $\mathrm{Vd}$ и Vs - величина потока соответственно в диастолу и систолу.

Оценивая кривую наполнения и перечисленные параметры каждого графта, выявляли критические показатели DF меньше 50\% и/или PI более 5, при которых следует провести ревизию шунта и, при необходимости, перешить дистальный анастомоз. Низкая ОСК также может свидетельствовать о плохом функционировании графта, ее следует оценивать в корреляции с двумя другими показателями.

\section{РЕЗУЛЬТАТЫ}

Исследование проведено в целях изучения влияния техники шунтирования на непосредственные интраоперационные параметры скорости кровотока по шунтам при операциях АКШ. Исходя из полученных данных (табл. 3) ОСК и сопротивления току крови по шунтам, поток по последовательным шунтам у пациентов группы $1-(70,6 \pm 30,2)$ мл/ мин значительно больше, чем по линейным шунтам у пациентов группы $2-(37,5 \pm 20,5)$ мл/мин. В соответствии с этими данными, ОСК увеличивалась линейно по мере увеличения числа анастомозов, в то время как РI пропорционально уменьшался. Это свидетельствовало о значительном гемодинамическом преимуществе последовательного коронарного шунтирования. Опасения относительно потенциального риска высокопроксимальной окклюзии последовательного шунта, обусловливающей ишемические события в миокарде одновременно в бассейнах нескольких ВА, ограничивали более активное использование последовательной техники шунтирования. Однако такие ишемические события возникают редко, что описано в литературе.

\section{ОБСУЖДЕНИЕ}

Несмотря на существенное улучшение хирургической техники, оперативное лечение ИБС только паллиативное. По данным литературы [7, 8], через 10 лет до 50\% венозных шунтов закрываются, 25\% - функционируют с значимым атеросклеротическим сужением, 10-15\% графтов закрываются в первый месяц после операции, что чаще всего обусловлено техническими ошибками при наложении анастомозов и выбором неправильной техники шунтирования, которую следует подбирать у каждого больного индивидуально. Использование интраоперационной оценки параметров кровотока по шунтам, в том числе последовательным, по данным флоуметрии сводит к минимуму риск технических ошибок при наложении анастомозов и частоту ранних ишемических событий.

\section{выводы}

1. Высокая скорость тока крови по проксимальной части последовательного шунта, низкое сопротивление току и большой объемный резерв крови его дистальной части значительно снижают риск возникновения тромбоза и окклюзии графтов.

2. Последовательное КШ имеет важные преимущества по сравнению с линейным шунтированием, что дает право использовать методику у пациентов при ИБС.

\section{ЛИТЕРATУPA/REFERENCES}

1. Akchurin RS, Shirjaev AA. Aktualnye problemy koronarnoj hirurgii. Moskva: Gjeotar-Med; 2004.108 p. [In Russian].

2. Oz BS, Lyem H, Akay HT. Mid-term angiographic comparison of sequential and individual anastomosis techniques for diagonal artery. $J$ Card Surg. 2006;21: 471-4.

3. Christenson JT, Schmuziger M. Sequential venous bypass grafts: results 10 years later. Ann Thorac Surg. 1997;63:371-6.

4. Kieser TM, FitzGibbon GM, Keon WJ. Sequential coronary bypass grafts. Longterm follow-up. J Thorac Cardiovasc Surg. 1986;91:767-72.

5. Di Giammarco G, Pano M, Cirmeni S, Pelini P, Vitolla G, Di Mauro M. Predictive value of intraoperative transit-time flow measurement for short-term graft patency in coronary surgery. Ibid. 2006;132:468-74.
6. Barner HB, Farkas EA. Conduits for coronary bypass: vein grafts. Korean J Thorac Cardiovasc Surg. 2012; 45(5): 275-286.

7. Vural KM, Sener E, Taşdemir O. Long-term patency of sequential and individual saphenous vein coronary bypass grafts. Eur J Cardiothorac Surg. $2001 \mathrm{Feb} ; 19(2): 140-4$.

8. Tokuda Y, Song M-H, Oshima H, Usui A, Ueda Y. Predicting midterm coronary artery bypass graft failure by intraoperative. Ann Thorac Surg. 2008;86:532-6. 